\title{
ANÁLISE DE CONTEÚDO COMO FERRAMENTA PARA A CONSTRUÇÃO DA EDUCAÇÃO AMBIENTAL DOS PECUARISTAS FAMILIARES DO ALTO CAMAQUÃ
}

\section{ANALYSIS CONTENT AS TOOL FOR CONSTRUCTION OF ENVIRONMENTAL EDUCATION OF THE FAMILY RANCHERS THE ALTO CAMAQUÃ}

\author{
Cibelle Machado Carvalho', Leonardo Machado Carvalho² \\ ${ }^{1}$ Gestora Ambiental. Especialista em Educação Ambiental. Mestre em Engenharia Ambiental pela Universidade \\ Federal de Santa Maria. Santa Maria/RS, Brasil. \\ ${ }^{2}$ Acadêmico do curso de Ciências da Computação - UFSM. Santa Maria/RS, Brasil.
}

\begin{abstract}
Resumo
Uma característica fundamental da pecuária familiar do Território do Alto Camaquã é sua dependência pelos recursos naturais. O uso destes recursos necessita de estratégias conscientes por partes dos atores locais. Deste modo, buscou-se com este estudo compreender as representações das comunidades locais. Construiu-se um modelo conceitual 'ideal' e um roteiro de entrevista qualitativo. As metodologias de investigação social utilizadas são análise de conteúdo e fundamentos da teoria da representação social e de pesquisa social qualitativa de Marília Cécilia Minayo. A análise dos resultados propiciou conhecer as potencialidades e dificuldades perante metodologias de educação ambiental e diagnosticar as idéias e percepções, representações dos pecuaristas sobre manejo de campo e água, escassez hídrica, água e qualidade de vida e a influência na produção pecuária. As idéias de flexibilidade para diversas práticas educacionais, experiência no campo com agregações de sentimentos emocionais de medo e tristeza, foram algumas das características encontradas nas representações sociais dos pecuaristas familiares.
\end{abstract}

Palavras-chave: Representação social, Educação ambiental, Alto Camaquã.

\begin{abstract}
A key feature of familiar livestock of Alto Camaquã is its dependence by natural resources. The use of these resources needs more conscious strategies by parts of local actors. Thus, we attempted to in this study to understand the representations of local communities. For that, it constructs an 'ideal' conceptual model and a screenplay of qualitative interview. The methodologies of social investigation used are analysis of content and fundaments from the theory of social representation by Serge Moscovici and from social qualitative research by Marilia Cecilia Minayo. The analysis of results provides to know the potencialities and difficulties before methodologies of environmental education, lately, the ideas and perceptions, representations of ranchers about management countryside and water, hybrid shortage, water and life quality and the influence in the livestock production were diagnosed. The ideas of flexibility to several educational practices, experience in the countryside with aggregations of emotional feelings of fear and sadness, were some characteristics in social representations from familiar ranchers.

Key words: Social representation, Environmental education, Alto Camaquã
\end{abstract}




\section{Introdução}

O território do Alto Camaquã está localizado na Serra do Sudeste do Estado do Rio Grande do Sul, região do Escudo Cristalino Sul-Rio-Grandense, à montante da Bacia Hidrográfica do Rio Camaquã. É uma região predominantemente de pecuária familiar, principalmente em sua produção - uma relação intensificada com os recursos naturais (TRINDADE et al., 2010). Essa região do Alto Camaquã é composta por uma notória beleza do bioma Pampa, com aflorações rochosas, vales, plantas endêmicas e com pouca degradação ambiental, rara beleza paisagística, além de solos rasos e pedregosos, pouco produtivos no contexto da agricultura. (DADALT, 2010; NESK, 2009; TRINDADE et al., 2010).

As características geológicas do território e a classificação para o levantamento das potencialidades das águas subterrâneas do Estado do RS (Mapa Hidrogeológico) estabelecem que o sistema de aquífero da região do Alto Camaquã é limitado de baixa possibilidade em rochas com porosidade intergranular. Essa análise compreende que a construção de poços tubulares não seria a melhor alternativa para abastecimento humano e dessedentação de animais.

Esse território pertence à chamada "nata" do Bioma Pampa (Figura 1), pois compreende uma região que por suas características econômicas e socioambientais ainda mantém um ecossistema a priori estável, preservando ainda alguns sistemas vegetais, hídricos e geológicos naturais da região. Embora a Bacia Hidrográfica seja delimitada geograficamente pelos municípios de Bagé, Caçapava do Sul, Lavras do Sul, Pinheiro Machado, Piratini e Santana da Boa Vista, Encruzilhada do Sul e Canguçu, nesta pesquisa iremos abordar apenas as cidades de Pinheiro Machado e Piratini.

Os pecuaristas familiares sofrem ao longo dos seus 150 anos de ocupação com a carência da gestão de recursos hídricos, além disso, no decorrer da última década, juntamente com severas mudanças climáticas e ocupação incorreta do solo, há significativos retrocessos na quantidade e qualidade da água disponível. Em contrapartida, as formas de relação com a natureza constituem-se como um conjunto de conhecimentos herdados num processo coevolucionário e que é ainda possível encontrar nas unidades familiares uma racionalidade ecológica (NESCK, 2009).

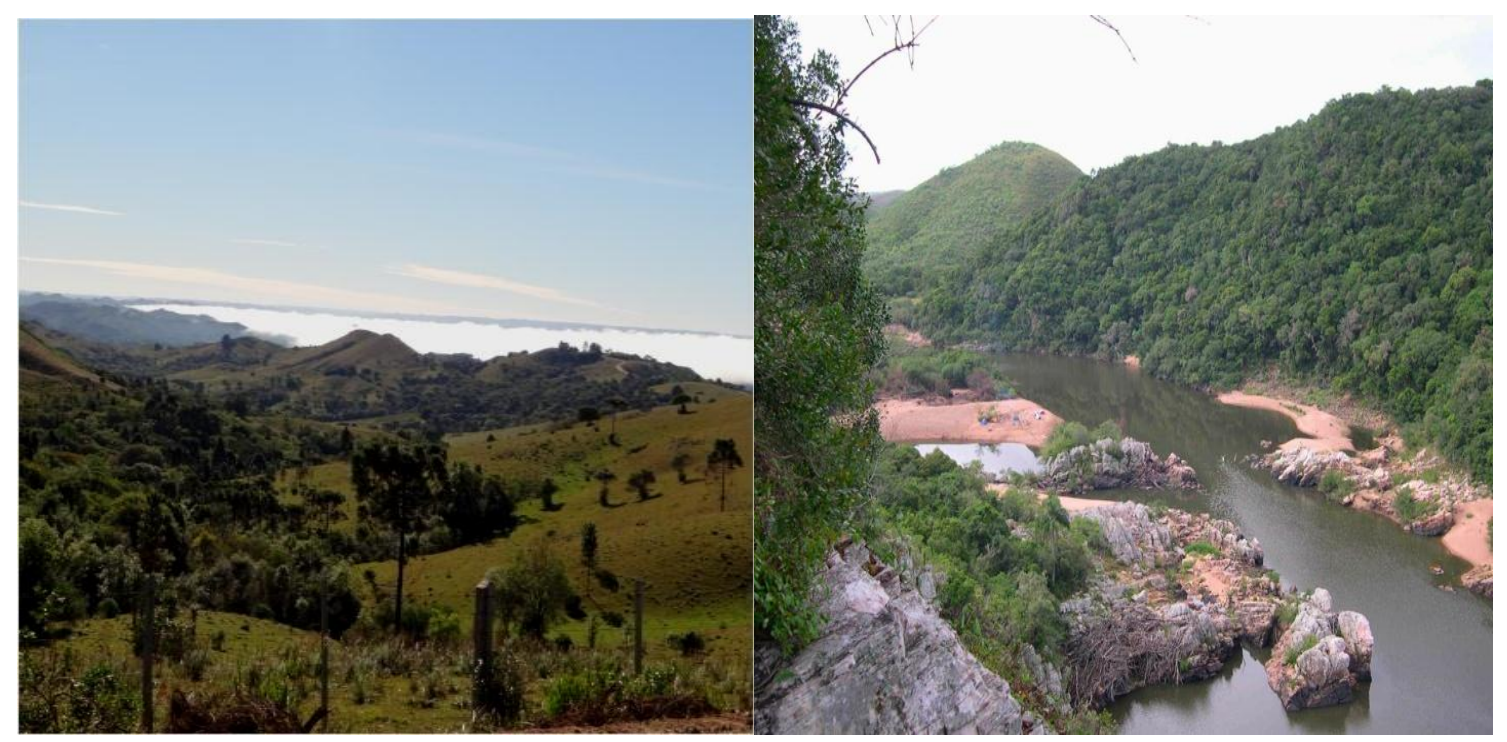

Figura 1: Paisagem típica do território do Alto Camaquã

Fonte: Acervo LABECO CPPSUL e LICA, 2012 
A ausência de um sistema público de distribuição de água e a cultura local faz com que a população rural do Alto Camaquã utilize, ao longo dos anos, as nascentes como fonte de água para subsistência e abastecimento no território, ou seja, adaptando-se de métodos para vencer esse problema, as cacimbas (CARVALHO, 2012).

A complexidade do Alto Camaquã deriva de uma situação de modernização incompleta, em função de um conjunto particular de características socioambientais e econômicas. Essa região não chegou a se transformar através da implantação em larga escala da agricultura tradicional nem da agricultura moderna, mantendo-se assim, com uma alta dependência dos recursos naturais (TRINDADE et al., 2010).

A pecuária familiar do território do Alto Camaquã tem importância estratégica na bacia hidrográfica, ainda que, vistas como "pobres e atrasadas", pois sem o extrativismo de água dos poços tubulares, os aquíferos ficam protegidos da retirada de grandes quantidades de vazões, assim, favorecendo a conservação da bacia. Observam-se estratégias de manejo que têm se transmitido por gerações, garantindo assim, a importância da continuidade dessas ações (OVERBECK, 2009; BORBA et al, 2009).

A forma diferenciada dos serviços ambientais prestados, dependência dos recursos naturais e o grau de modificação da bacia pelos pecuaristas familiares do território do Alto Camaquã, são primordiais e determinantes para a manutenção, produtividade e conservação das águas da Bacia Hidrográfica do Rio Camaquã. A disponibilidade hídrica desta bacia vem se mantendo principalmente por combinações de características culturais e socioeconômicas do Alto Camaquã. A agricultura e silvicultura depende da supressão completa ou parcial dos campos sulinos, a pecuária familiar não. A vocação econômica verdadeiramente sustentável da região pampeana são as atividades pastoris (OVERBECK, 2009)

Os conflitos hídricos existentes no território do Alto Camaquã demonstram a necessidade de abordar políticas, estratégias e diagnosticar a área para projetos mais conscientes de educação ambiental hídrica, obtendo resultados mais concisos para uma população que se utiliza predominantemente da água das nascentes. A importância dos recursos naturais potencializa a busca e a construção de estratégias duráveis de gestão e metodologias de educação de recursos hídricos.

Nesse contexto, o objetivo geral orientador deste estudo é diagnosticar e estudar a representação social das pecuaristas familiares do Alto Camaquã a partir da análise de conteúdo como possíveis ferramentas metodológicas de Educação Ambiental Hídrica. Interessa conhecer seus processos perceptivos e imaginários em um contexto cultural, visando conhecer os valores, ideias e práticas da população, para que se possa proporcionar uma educação adequada para famílias de pecuaristas familiares enfatizando o gerenciamento do uso, distribuição, captação e tratamento doméstico do recurso hídrico. Com esta pesquisa, obteremos o re-conhecer do âmbito e do potencial natural, humano e produtivo para uma melhor eficiência da educação ambiental com ênfase no uso da água, minimizando, assim, a intensidade do impacto causado pela escassez do recurso hídrico na pecuária familiar.

\section{Estratégias metodológicas}

O uso do método qualitativo é válido porque favorece ao pesquisador a descrição da complexidade do problema da pesquisa, possibilitando compreender os processos dinâmicos vividos pelos campos sociais e entender as particularidades das categorias envolvidas (RICHARDSON, 1999). A pesquisa qualitativa não se baseia no critério numérico para garantir representatividade, assim, a amostragem boa é aquela que possibilita abranger a totalidade do problema investigado em suas múltiplas dimensões (MINAYO, 2010).

Assim, com enfoque da pesquisa é em entender os saberes sociais dos pecuaristas familiares, utilizou-se o método da pesquisa social qualitativa (MINAYO, 2000), a orientação exploratória (GIL, 2006) e as teorias das representações sociais (MOSCOVICI, 2011). Centrando-se na análise da construção e transformação do conhecimento social a fim de elucidar como a ação e o pensamento 
interligam-se na dinâmica social. Assim, foram aplicados 24 roteiros de entrevistas, constituídos de 21 perguntas, nos distritos do Barrocão ${ }^{2}$, Capela e Alto Bonito, respectivamente, nos município de Piratini e Pinheiro Machado do Estado do Rio Grande do Sul.

O critério mais importante de amostragem é a identificação do "universo" de representações. As entrevistas foram realizadas até o ponto em que obtivessem suficiência amostral, ou seja, uma saturação de "ideias" na medida em que novas entrevistas eram realizadas e os resultados se repetiam (MINAYO, 2000). A escolha não aleatória pressupõe que os indivíduos sejam intencionalmente selecionados para o estudo proposto (CRESWELL, 2010).

No tratamento e análise dos dados foi utilizado o programa Microsoft Office Excel. Fez-se o uso da análise de conteúdo, técnica em que os dados brutos são sistematizados e agregados em categorias, permitindo uma descrição exata das características pertinentes ao conteúdo expresso no texto (OLIVEIRA, 2008). Dessa forma, foi possível colocar em evidência as informações fornecidas, utilizando a categorização (MATTE, 2013).

Após a coleta de dados, as informações foram organizadas e tabuladas, sendo sua análise distinta naquilo que confere à qualidade dos dados, realizando a interpretação, a explicação e a especificação das ideias e da relação entre elas, correlacionando os resultados ao aporte do modelo conceitual. Essa tem o objetivo de captar, descrever e analisar percepções desses grupos ocasionais de informantes em entrevista oral, no qual incorpora novos recursos para lidar com as interpretações que resultam dessas falas (MOSCOVICI, 2011). As etapas para a análise de conteúdo seguiram os passos orientados por Creswell (2009). Em um primeiro momento foram transcritas as entrevistas sendo organizadas com as respectivas perguntas e objetivos. Posteriormente, foram relidas para um panorama geral da pesquisa e a terceira etapa consistiu na categorização das respostas, consistindo em um processo de organização do material. A Análise de Conteúdo permite visualizar os núcleos organizadores dos discursos, as variáveis e categorias, bem como os conflitos e consensos estabelecidos pelas pessoas dos grupos estudados. Essa metodologia possibilita observar os dados por meio de uma visão ampla, na qual a totalidade do material coletado permite levantar categorias do grupo (REIS e BELLINI, 2011). Bardin (1978) afirma que a análise de conteúdo se faz pela técnica de codificação, transformando os dados brutos do discurso, por recorte, agregação e enumeração, permitindo atingir uma representação do conteúdo. Segundo Bardin (2009) tratar o material é permitir sua expressão, susceptível esclarecer ao analista certas características do texto. A análise de conteúdo também permite uma descrição objetiva, sistemática e quantitativa do conteúdo manifesto de uma comunicação na medida em que favorece a delimitação do corpus, a definição de termos, descrição das características das mensagens, as inferências sobre as causas e efeitos (CAZENEUVE; VICTOROFF, 1982). Matte (2013) afirma que uma forma de complementar a análise é utilizar as narrativas dos discursos, fotos captadas durante a expedição a campo como adjunto ás discussões, complementando a análise, assim, confirmando os resultados.

\footnotetext{
${ }^{2}$ Nas expedições a campo percebeu-se que o distrito do Barrocão é considerado o território de maior vulnerabilidade hídrica do território do Alto Camaquã, em vista dessa problemática, o número de entrevistados nessa localidade foi maior.
} 


\section{Fluxograma Metodológico:}

A figura 2 expressa o fluxo metodológico desta pesquisa.

\section{Expedição a campo/ construção da problemática de pesquisa}
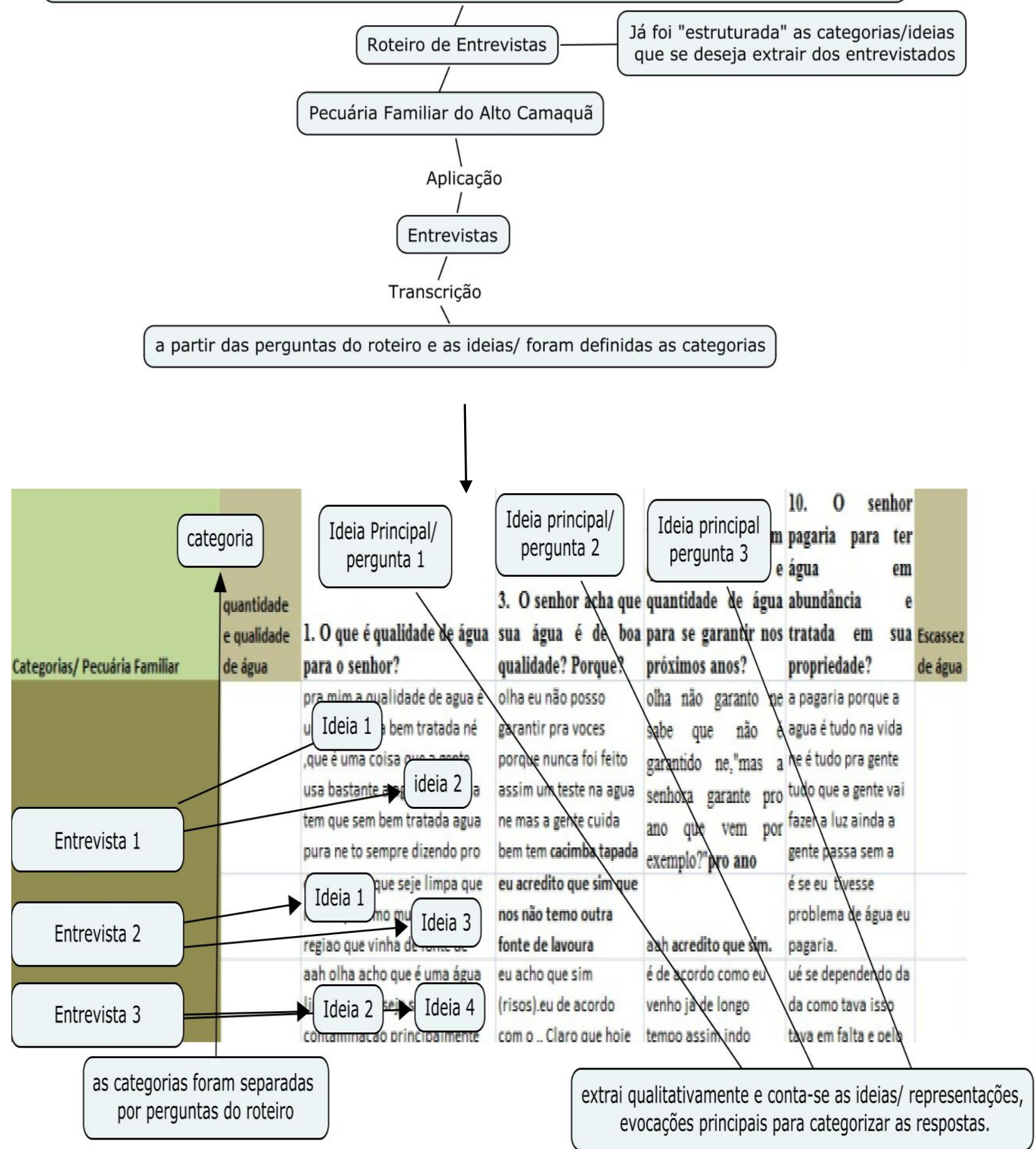

Figura 2: Fluxograma Metodológico da análise de conteúdo. Fonte: Autor

Conforme, mostrado na figura 2, a ideia principal, estabelecida pelos autores e que definiu a estrutura do questionário, não será a mesma ideia extraída necessariamente. $\mathrm{O}$ roteiro de entrevista 
deve ser tratado e analisado, antes das saídas a campo, para melhor seqüência na elaboração de diário de campo e transcrições das entrevistas. Após as transcrições, são identificadas e categorizadas novas ideias dos discursos e de cada resposta do entrevistado. Esta sequência é fundamental para o pesquisador estabelecer o que quer extrair. Este procedimento resulta em uma hierarquia de ideias, em dois níveis, a ideia principal e as ideias secundárias, que correspondem a ideia 1, ideia 2, e assim sucessivamente, para cada pergunta

\section{Resultados e discussões}

Para melhor uma melhor apresentação, ordenação e compreensão dos resultados do estudo as respostas dos participantes foram agrupadas em 3 categorias.

\section{Categoria 1: Características e contextos no manejo do campo}

Todos os respondentes percebem a relação do solo, planta e animal, e sua dependência um do outro conforme já relatamos nesta seção de resultados. Porém a maioria não percebe a água como primordial para esse sistema vivo. As principais ideias atreladas a esta categoria são sobrevivência, ciclo, integração e produção. A percepção de sobrevivência está encadeada na ideia de que o solo, planta e animal não sobrevivem um sem o outro, no entanto, os respondentes não encaram o homem como intermediador desse sistema. O ciclo e integração estão interligados na representação de que planta advém do solo e é a alimentação primordial para os animais. A produção está representada com o cuidado e fertilidade do solo, "o solo não castigado", para ter qualidade do animal.

De acordo com Reigota (1995), a ideia de uma natureza transformada pela ação humana aparece com maior dificuldade, haja vista a impossibilidade de incorporarem espontaneamente questões que satisfaçam a totalidade do problema.

$\mathrm{Na}$ representação de um campo bom que rende mais carne por hectare, foram constatadas oito ideias centrais, campo com grande quantidade de água, pastagem, campo de várzea, solo macio e fértil, além de campos com menor quantidade de "pedras", campo limpo e manejo adequado.

A maioria dos entrevistados atrelou a ideia de pastagem à elevada dependência dos recursos forrageiros naturais, que consideram umas das características marcantes da pecuária familiar. A água foi a segunda ideia mais citada, devido à dificuldade em épocas de escassez e estio. O Barrocão localizado no município de Pinheiro Machado tem grande proporção de nascentes não perenes - fluxo de água estacional (CARVALHO, 2012), estabelecendo um critério de vulnerabilidade, visto que, são poucas nascentes perenes nessa localidade. Essa situação confirma a preocupação da ideia de água como um critério para se ter um campo "bom" para a criação de gado.

Outra ideia representada foi área de várzea e campo "macio" que supostamente foram estabelecidos por campos úmidos e argilosos, áreas baixas, vegetação rasteira, sem afloramento de rochas e solo não compactado, normalmente área apta para o arroz, atrelada a ideia de campo "limpo". Campo macio foi representado como uma terra fértil e pastagem "boa". Essa representação foi bastante difundida pelos pecuaristas devido à distância de poucos quilômetros que já existem esse tipo de campo descrito.

E por fim, o manejo foi citado quatro vezes, buscando a ideia de Reigota (1995) ao afirmar que as relações são recíprocas entre a natureza e o homem, e as estratégias de manejo se transmitem por gerações, garantindo assim, a importância da continuidade dessas ações (OVERBECK, 2009; BORBA et al., 2009).

$\mathrm{Na}$ verificação da percepção em relação à produtividade natural dos campos, os resultados gerados, por ordem de evocação, são seis: manejo, limpeza, adubar o solo, plantação de azeven e clima. A maioria citou quanto ao manejo, a divisão de piquetes, descanso do solo e reserva de pasto, 
afirmando o conhecimento empírico através da observação dos seus cotidianos, assim, atrelando a racionalidade ecológica dos pecuaristas familiares.

A evocação da flexibilidade dos pecuaristas para diferentes práticas, através das reuniões nas associações, foi positiva, tornando-se um potencializador coletivo. Deste modo, estabeleceu três grupos distintos. O primeiro grupo, começou as práticas de manejo através das reuniões, enquanto o segundo grupo já estabelecia um conhecimento empírico. As reuniões foram apenas incentivadoras do processo. O terceiro grupo é restrito, reconhece o valor benéfico das metodologias, no entanto, ainda não as pratica por falta de conhecimento e por práticas culturais da família.

Ao verificar, ideias de aperfeiçoamento do manejo de campo, foram representadas três ideias: água no manejo, conhecimento e maiores divisões na propriedade.

\section{Categoria 2 : Escassez da água}

Na representação da categoria escassez de água foi perguntado, se pagaria e quanto se pagaria para ter água em sua propriedade, foram evocados quatro grupos distintos. Grupo 1: os que valoram a água como um atributo de maior importância e representaram simbolicamente como "pagaria qualquer preço". Assim, este grupo mostrou agregação de valor sentimental e emocional, e possívelmente foram os que mais sofreram com a escassez de água no ano de 2012.

O segundo grupo representou um valor monetário, no qual , todos representaram como condição de pagamento, ou seja, valoraram de acordo com sua renda mensal e anual.

O terceiro grupo representou água como forma de bem ambiental, acessível e advinda pela natureza, pagar pela água é algo não representado, visto que, a natureza é utilizada por todos e é gratuita. Eles também estabeleceram um ato de cuidado por suas cacimbas e nascentes.

O quarto grupo estabeleceu contrariedade no pagamento pelo acesso à água, por ordem de evocação, afirmaram ter água de qualidade e quantidade, visto que, moram a poucos quilômetros do Rio Barrocão.

$\mathrm{Na}$ representação de pensamento da escassez hídrica, foram tabuladas três ideias centrais, nas quais medo, tristeza, pavor e preservação foram as palavras mais repetidas. O primeiro grupo mostrou preocupação em construir fontes de água para armazenamento. $\mathrm{O}$ segundo representou o cuidado com a preservação das suas fontes naturais, e o terceiro grupo com $60 \%$ dos respondentes mostrou um sentimento de medo, tristeza, pobreza e miséria.

Na identificação de existência de obras hidraúlicas e a percepção dos atos através da alteração de distribuição de água, foram relatadas três ideias distintas. Por acondicionamento de relatos, o primeiro grupo reconhece que açudes, cacimbas e bebedouros podem alterar a distribuição de água da propriedade, ou seja, reconhecem que seus atos podem transformar o meio. O segundo grupo tem recursos hídricos em suas propriedades, não encontrando necessidade de obras, açudes e bebedouros e não reconhecendo a cacimba como distribuidora de água. E o terceiro grupo relatou a inexistência de quaisquer tipo de distribuição de água, por motivos ambientais e monetários.

\section{Categoria 3: Água e qualidade de vida}

Água é um elemento vital para a sobrevivência dos seres vivos, e sem ela não seria possível vida em nosso planeta. No princípio da humanidade, o consumo de água estava restrita aos usos "essenciais": bebidas e preparo de alimentos. Com o desenvolvimento de hábitos de higiene e com a indústria, o consumo aumentou consideravelmente. Hoje o homem precisa de água em quantidade suficiente e qualidade adequada para atender todas suas necessidades, ou seja: higiênica, alimentar e industrial e outras (SOUZA, 2000). 
Partindo desse pressuposto, as representações de qualidade de vida com ênfase na água dos pecuaristas familiares são misturadas com sentimentos de permanência. O grau de relevância nos dias atuais foi dividido em duas ideias: os pecuaristas que consideram um problema contínuo e permante, principalmente pelo controle desenfreado pela procura por água e os que consideram um problema apenas para o verão, pelas chuvas descontínuas e carência de sistemas de captação de água.

Foi analisado o grau de importância da água, atribuída à qualidade de vida, para analisar como é representada o grau de vulnerabilidade dos pecuaristas. A primeira ideia representada foi a higiene pessoal e a alimentação. Possivelmente é o grupo mais vulnerável, representando a escassez de água no dia-a-dia.

O segundo grupo descreveu a água como fonte de vida e como essencial. A água é vital e essencial à vida vegetal, animal e humana, porém, quando contaminada é considerada um dos principais vínculos de doenças. $\mathrm{O}$ acesso à água potável e ao saneamento básico têm um papel preponderante na incidência de doenças. Este grupo mostrou preocupação com água sem tratamento contínuo.

O terceiro e, último grupo, representou a produção animal e a sede animal. Possivelmente, é o grupo que tem maiores problemas de distribuição de água na propriedade. Há necessidades de alternativas que impliquem na gestão ambiental e recursos hídricos da propriedade, adotando maneiras que não causem impactos no ambiente.

O ciclo hidrológico é um movimento contínuo no nosso planeta, refere-se à troca contínua de água na hidrosfera, entre a atmosfera, a água do solo, águas superficiais, subterrâneas e das plantas (THURMAN, 1993;TUCCI, 2007).

Os atores socias representaram o surgimento da água, em ordem de evocações: nascente, lençol freático, evaporação, nuvens, rios e solo. A maioria representou advinda do solo e da nascente. Possivelmente, é uma representação do dia-a-dia do pecuarista, visto que todos utilizam as cacimbas para abastecimento humano e grande parte para dessedentação animal.

\section{Categoria 4: Influência na produção pecuária}

A pecuária familiar e a paisagem do Alto Camaquã se mantêm através da agregação de fatores, onde características ambientais (terrenos declivosos e solos rasos) fornecem à bacia diversos serviços ambientais apesar dos usos. Essas características ambientais têm atuado como barreiras à modernização tecnológica produtiva do território (DADALT, 2010), e a dinâmica de manejo da pecuária familiar, baixa dependência de insumos externos, alta dependência dos recursos renováveis (BORBA; TRINDADE, 2009) com a heterogeneidade local. A baixa interferência humana sobre os ecossistemas naturais demonstra a existência de dinâmicas produtivas específicas que são determinadas por relações construídas entre o "homem-cultural" local e a natureza (NESK, 2009).

Os pecuaristas familiares representaram a experiência no campo, manejo, pastagem e chuva como os principais fatores de produção, retomando resultados de pesquisas anteriores sobre a baixa interferência tecnológica.

A ideia principal sobre os atributos naturais que mais faz falta e são necessários para a venda de um animal de qualidade para a indústria é a venda sem intermediários e a genética. Os respondentes não representaram os atributos "naturais" como, meio ambiente e a natureza, no qual, não se atribui valor monetário, mas sim atribuíram as dificuldades de venda de um animal.

No meio rural, os resíduos domésticos e os dejetos animais não são tratados - ou são parcialmente tratados. Sabe-se que a poluição pontual contribui enormemente para a poluição da água superficial, que é uma contaminação que ocorre na natureza por todo tipo de resíduo orgânico ou inorgânico, inserido pelo homem, sendo possível identificar o local de onde advém um determinado poluente (CASALI, 2008). 
As três principais ideias atreladas à eliminação dos resíduos sólidos é queimar, enterrar e a associação. A maioria dos pecuaristas familiares elimina os resíduos nas associações para, posteriormente, serem eliminados no aterro controlado mais próximo pela prefeitura local.

As atividades no meio rural necessitam estar em equilíbrio com a manutenção dos recursos hídricos, uma vez que utilizam esses recursos de forma direta para sustentar seus processos. Entretanto, ainda alguns pecuaristas queimam e enterram seus resíduos sólidos, principalmente pela cultura, costumes e hábitos, além do que a gestão pública oferece um processo mais lento a ser empregado devido à distância no meio rural.

Na percepção do que faz ser um ano bom e um ano ruim, todos os atores sociais atrelaram a ideia de chuvas contínuas e boa produção. As expedições a campo no ano de 2012 nos mostraram invernos e verões rigorosos e chuvas irregulares. A representação social desse grupo de um ano ser bom ou ruim está relacionado às chuvas regulares, em vista do ambiente vivido naquele período.

Portanto, foi observado que o mau gerenciamento pode tornar o recurso escasso, além de comprometer a qualidade. Existem soluções de manejo para que a água da chuva seja aproveitada adequadamente para a subsistência das famílias e produção pecuária.

Porém, informar e educar a sociedade para um problema de dimensão universal é a principal dificuldade, pois grande parte dos Pecuaristas Familiares não acredita que possa perturbar o meio ambiente ao ponto de minimizar os recursos naturais disponíveis. A água é fator primordial para o sustento à vida. As análises metodológicas, utilizadas a campo, contribuíram para o aprendizado de técnicas e procedimentos adotados para realizar o início de uma estratégia de educação que requer tempo e dedicação. Enfatizar os problemas de recursos hídricos na educação proporciona uma base para um pensamento sistêmico, pois a disponibilidade de água em certas regiões do Alto Camaquã é escassa ou mal gerenciada.

\section{Considerações finais}

Sato (2004), afirma que a educação ambiental deve buscar sua eterna recriação, avaliando seu próprio caminho na direção da convivência coletiva e da relação da sociedade diante do mundo. Segundo Reigota (1995), o meio ambiente é muito mais do que os ambientes naturais que costumamos imaginar e que devemos ter uma visão globalizante de meio ambiente, que considere as relações recíprocas entre natureza e sociedade.

Recomenda-se que a partir das representações, resultados e discussões deste artigo, construa-se alternativas de oficinas de educação ambiental, através das associações, aspecto considerado importante na comunidade. Andrade et al. (1995), afirmam que as oficinas têm, por excelência, a dinâmica, a velocidade e o movimento harmônico. É a intenção viva da descoberta, por parte de todos, pensando, fazendo, criando, experimentando, discutindo.

As oficinas educacionais seriam atreladas à pesquisa-ação, com o intuito de construção metodológica juntamente com o pecuarista e seu cotidiano. É uma metodologia já aplicada no território do Alto Camaquã, em uma perspectiva teórico-filosófica e político-pedagógica, de forma crítica, partindo de uma reflexão de suas premissas, que antecedem as práticas isoladas, levando em conta a construção do conhecimento na forma de consultorias, oficinas participativas, incluindo leituras, imagens, vídeos, trabalho em grupo, jogos, dinâmicas, vivências e sensibilização (ZAKRZESKI E SATO, 2007; GUIMARÃES, 2004).

O primeiro aspecto a se considerar é a explicação do ciclo hidrológico, capacitando os atores sociais sobre a gestão eficiente, equilibrada e sustentável dos recursos hídricos no âmbito da Bacia Hidrográfica do Rio Camaquã. Apesar das dificuldades, como falta de medidas estruturais e nãoestruturais de educação hídrica para o consumo consciente de água das nascentes do Alto Camaquã, a única alternativa de abastecimento humano e dessedentação animal são as nascentes e a precipitação. 
Posteriormente, pode-se discutir o que é Comitê de Gerenciamento da Bacia Hidrográfica do Rio Camaquã e suas atribuições a partir da bacia como unidade de gestão.

Outro aspecto relevante é a importância do manejo de campo na realidade diária do pecuarista, visto que já representam como algo importante, através do processo positivo e negativo da planta, solo e animal. Existem metodologias que poderiam ser aplicadas sobre infiltração em solos com pastagem e solo descoberto. As estratégias utilizadas podem ser voltadas à abertura de horizontes reflexivos, tentando romper com os tradicionais discursos verificados na prática educativa (CASCINO, 2007), e que associem teoria e prática.

Grande parte dos pecuaristas pagaria para ter água em abundância em sua propriedade, em vista disso, trabalham manejo de nascentes, recuperação de áreas degradadas e fontes alternativas de armazenamento e captação de água, para diminuir a sensação e representação de medo.

Como há ausência de saneamento básico e presença de fossa negra, normalmente utilizada na área rural, poderiam ser propostas unidades experimentais de sistema simplificado econômico, prático e viável de tratamento de água de uso doméstico, para a melhoria da qualidade da água destinada ao meio ambiente. A fossa negra é a principal responsável pela contaminação das águas subterrâneas que abastecem as nascentes, podendo influenciar na quantidade e na qualidade da água ofertada. A otimização do uso das águas nas propriedades rurais é uma alternativa para os pecuaristas que são vulneráveis às mudanças climáticas, podendo retomar a estabilidade ecossistêmica do ambiente em sua propriedade.

Sabe-se que a poluição pontual contribui enormemente para a poluição da água superficial (MACIEL; FARIA, 2013). O conceito de "substituição de fontes" se mostra como a alternativa mais plausível para satisfazer as demandas menos restritivas, liberando as águas de melhor qualidade para usos mais nobres, como o abastecimento doméstico. As águas de qualidade inferior, sempre que possível, devem ser consideradas como fontes alternativas para usos menos restritivos.

Uma das soluções viáveis para o território do Alto Camaquã é a utilização de uma fossa séptica biodigestora de resíduos orgânicos para fim de reuso de água. Essa pesquisa foi realizada pela Embrapa Instrumentação Agropecuária, foi premiada pela Fundação Banco do Brasil de Tecnologia Social em 2003 e tem a intenção de alternativas de uso de água menos nobre.

A partir das representações sociais pode se estabelecer diversas metodologias educacionais, através dos saberes e cotidiano dos pecuaristas, já que, ninguém educa ninguém, ninguém educa a si mesmo, os homens se educam entre si, mediatizados pelo mundo (FREIRE, 1984). Portanto, este artigo abordou o tema das representações sociais dos pecuaristas familiares do Alto Camaquã como estratégia de educação ambiental. $\mathrm{O}$ estudo versou sobre a representação social sob uma perspectiva do modelo conceitual ideal, procurando dar ênfase ao ciclo da água, compreendendo os aspectos culturais, as crenças, os valores, as ideias, vulnerabilidades dos pecuaristas familiares.

Para se responder as questões da pesquisa e os objetivos propostos, fez-se o uso integrado de abordagem das teorias das representações sociais de Serge Moscovici e o método da pesquisa social qualitativa de Marília Cécilia Minayo, como forma de compreender os aspectos representativos e simbólicos dos atores sociais. As ferramentas analíticas oferecidas nessas respectivas abordagens, dentro dos limites impostos por esta escolha, permitiram entender a problemática que se propôs a análise deste estudo.

Com isso, compreendeu-se as principais ideias atreladas ao ciclo da água, manejo de campo e água, qualidade de vida, escassez de água e influência na produção pecuária, para estratégias de possíveis metodologias de educação ambiental.

Dessa maneira, é possível concluir que as representações sociais dos pecuaristas familiares do Alto Camaquã são caracterizadas pelo seu modo de vida, sentimento de medo pela escassez hídrica e outro aspecto fundamental é a importância que se dá as experiências no meio rural.

De tal modo, a liberdade para escolher a melhor estratégia de educação ambiental às situações de representação, se dá com as construções de pesquisa-ação, junto com o pecuarista. Este estudo serve para conhecer os pensamentos e ideias atreladas a cada vulnerabilidade estabelecida no modelo conceitual que servem como ponto de partida. 
Desse modo, os resultados desta monografia apontam para uma nova contribuição acadêmica sobre o tema da representação social para metodologias de educação ambiental, assim como reúnem subsídios para melhor atrelar estratégias de educação ambiental no território. Além disso, reúnem elementos importantes para oferecerem subsídios nas ações de políticas públicas, extensão e pesquisa, contribuindo assim para o exercício da educação ambiental eficiente.

Fica a certeza de que há necessidade de avanços sobre a abordagem de representação social e a educação ambiental atrelada a um conhecimento de saberes do cotidiano, e que novos estudos possibilitem avanços, apontando para soluções da realidade diária dos pecuaristas familiares e capacitando as populações rurais.

\section{Referências}

BARDIN, L. Análise de Conteúdo. São Paulo: Edições 70, 1978.

BORBA, M. La Marginalid como potencial para laconstrucción de otro "Desarrollo": El caso de

Santana da Boa Vista, Rio Grande do Sul, Brasil. Doutorado em Sociologia, Agroecologia e Desenvolvimento Sustentável, na Universidade de Córdoba, em 2002.

CALLON, M. Some Elements of a Sociology of Translation: Domestication of the Scallops and the Fishermen of St Brieuc Bay. In: LAW, J. (Comp.). Power, Action and Belief.A New Sociology of Knowledge? London: Routledge\& Regan Paul, 1986a, p. 196-223.

CAPRA, F. A teia da vida: uma nova compreensão científica dos sistemas vivos. São Paulo: Cultrix, 1996,256 p.

CARVAlHO, C. M.; BORBA, M. F. S. Avaliação das nascentes do território do Alto Camaquã/RS. Resumo Simples. Congrega, 2012.

CHRISTOFOLETTI, A. Modelagem de sistemas ambientais. São Paulo: Edgard Blucher, 1999, 236 p.

CPRM. Companhia de pesquisa de Recursos Minerais. Mapa Hidrogeológico do Estado do Rio Grande do Sul. Disponível em:<http://www.cprm.gov.br> Acesso em: 17.mar.2014.

CRESWELL, J. W. Projeto de pesquisa: métodos qualitativo, quantitativo e misto. Tradução Magda Lopes, 3. ed., Porto Alegre: Artmed, 2010, 296 p.

DADALT,L.P. Padrões de diversidade da vegetação lenhosa da região do Alto Camaquã, Rio Grande do Sul. Dissertação (mestrado) Programa de Pós Graduação em Ecologia, Universidade Federal do Rio Grande do Su,2010.

FIGUEIRÓ, A. S.; SELL, J. C.; LOSEKANN, M. B.; DEGRANDI S. M. Compreensão da paisagem do Alto Camaquã: debate ambiental sobre o bioma pampa. Mercator, Fortaleza, v. 10, n. 23, p. 147-158, set./dez. 2011.

FREIRE, P. Educação e Mudança. 8. ed. Rio de Janeiro: Paz e Terra, 1984, 79p.

GIL, A. C. Métodos e técnicas de pesquisa social. 5. ed. São Paulo: Atlas, 2006, 206p.

GUIMARÃES, M. Educação Ambiental. Duque de Caxias: Ed. Unigranrio, 2000. 
LEFEBVRE, H. A vida cotidiana no mundo moderno. São Paulo: Ática, 1991.

MINAYO, Maria Cecília de Souza (org.). Pesquisa social: teoria, método e criatividade.29. ed. 2004.

MOSCOVICI, S. Representações sociais: investigações em psicologia social. 8. ed. Petrópolis: Vozes, 2011. $404 \mathrm{p}$.

NESKE, M. Z. Estilos de agricultura e dinâmicas locais de desenvolvimento rural: o caso da pecuária familiar no território do Alto Camaquã do Rio Grande do Sul. 2009. 208 f. Dissertação (Mestrado em Desenvolvimento Rural) -Universidade Federal do Rio Grande do Sul, Porto Alegre, 2009.

OVERBECK, G. E. et. al. Os campos sulinos: um bioma negligenciado. In: PILLAR, V.P. [et. al]. Editores. Campos Sulinos: conservação e uso sustentável da biodiversidade. Ministério do Meio Ambiente-MMA, 2p. 24-41, 2009.

REIS, S. L. de A.; BELLINI, M. Representações sociais: teoria, procedimentos metodológicos e educação ambiental. ActaScientiarum.Human and Social Sciences.Maringá, v. 33, n. 2, p. 149-159, 2011.

RIBEIRO, C. M. Estudo do modo de vida dos pecuaristas familiares da região da campanha do Rio Grande do Sul. 2009. 304 f. Tese (Doutorado em Desenvolvimento Rural). Programa de PósGraduação em Desenvolvimento Rural, Universidade Federal do Rio Grande do Sul, Porto Alegre, 2009.

RICHARDSON, R. J. Pesquisa Social: métodos e técnicas.3.ed. São Paulo: Atlas: 1999.

SACHS, I. Population, developpementetemploi. Toulouse, Revue Internationale dês Sciences Sociales, n. 141, p. 409-426, Unesco/Erès, 1994.

SATO, M. Educação Ambiental. São Carlos: RiMa, 2004.

TRINDADE, J. P. P.; BORBA M. F. S.; LEFEVBRE, J. Território do Alto Camaquã: apresentação da cobertura vegetal do Alto Camaquã: junho de 2007. Bagé: Embrapa Pecuária Sul, 2010b, 13 p. (Embrapa Pecuária Sul. Documentos, 107). 